\title{
LA CRISIS DE LA CULTURA Y EL ARTE
}

\author{
GUILLERMO SANCHEZ FIERRO \\ Jefe del Departamento de Artes
}

JAIME RUIZ SOLORZANO

Jefe de Programa de Artes Visuales

Universidad Surcolombiana

\subsection{PROBLEMATICA DE LA CULTURA Y EL ARTE}

Posiciones y prácticas de hace unas décadas polarizaban el enfrentamiento entre las denominadas Cultura de élites (opresora) y Culturas populares (oprimidas), separándolas radicalmente y atribuyéndoles características diferenciadoras.

Respecto a la producción artística Arnold Hauser afirmaba: "como arte del pueblo se designa en las siguientes páginas de la actividad poética, musical y plástica de estratos

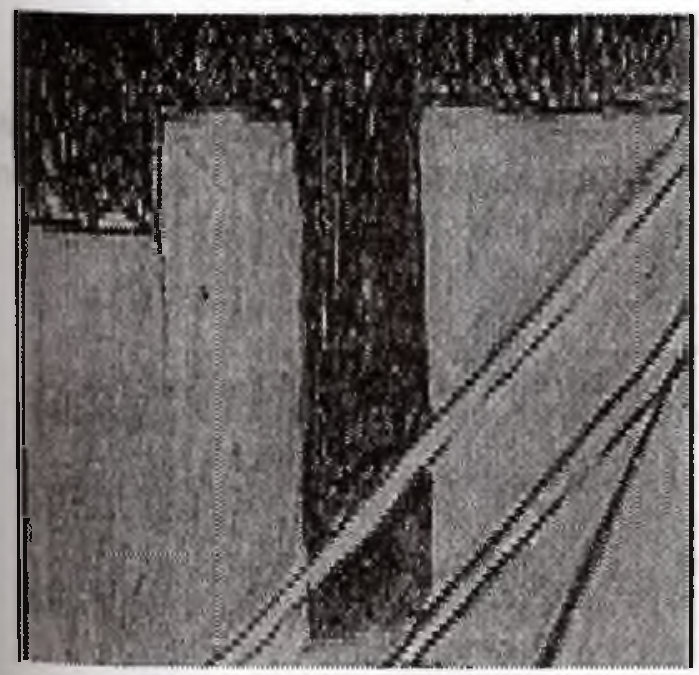

sociales carentes de ilustración y no pertenecientes a la población industrial y urbana. Esencial en este arte es que los miembros de estos estratos participan en él no sólo como sujetos receptivos, sino la mayoría de las veces también como sujetos creadores, a pesar de que no se destacan individualmente en este último sentido ni pretenden que se les reconozcan su condición de autores. Bajo la denominación de arte popular entendemos en cambio la producción artística o seudoartística que responde a las exigencias de un público predominantemente urbano, semiillustrado y tendiente a la masificación. En el arte del pueblo productores y consumidores apenas están separados entre sí y los límites entre ambos grupos son siempre fluctuantes; en el arte popular, en cambio, nos sale al paso un público improductivo artísticamente y pasivo en lo esencial y una producción profesional orientada estrictamente a la demanda.

Los rasgos negativos que separan el arte del pueblo y el arte popular del 
arte elevado, del arte de la clase ilustrada, de conocedores y entendidos, aparecen a primera vista más claros y decisivos que los rasgos positivos que unen aquellos con éste. Arte estricto, elevado, auténtico, el arte que significa siempre un enfrentamiento con los problemas de la vida y una lucha por el sentido de la existencia y que se nos presenta siempre con la exigencia "debe cambiar de vida", tiene poco que ver con el arte del pueblo, que apenas es algo más que juego y ornamento, ni con el arte popular, que nunca es más que entretenimiento y pasatiempo' ${ }^{\prime}$.

Posteriormente determina: el "Arte del pueblo no es un arte de la comunidad, sino como el arte de las clases superiores, un arte de clase y situación social $^{2}$., donde se evidencia claramente la teoría de la lucha de clases.

Acompañaban a estas aseveraciones la total negación del arte popular con expresiones como: "patrimonio cultural degradado"; su inferioridad: "el arte del pueblo se arrastra a larga distancia detrás del arte superior... esta distancia se ha calculado en cien años"; su acción destructora: "al popularizarse y rustificarse el arte de élite pierde no sólo su actualidad histórica, sino la mayoría de las veces su calidad artística"; su incapacidad de apreciar el valor estético: "el pueblo

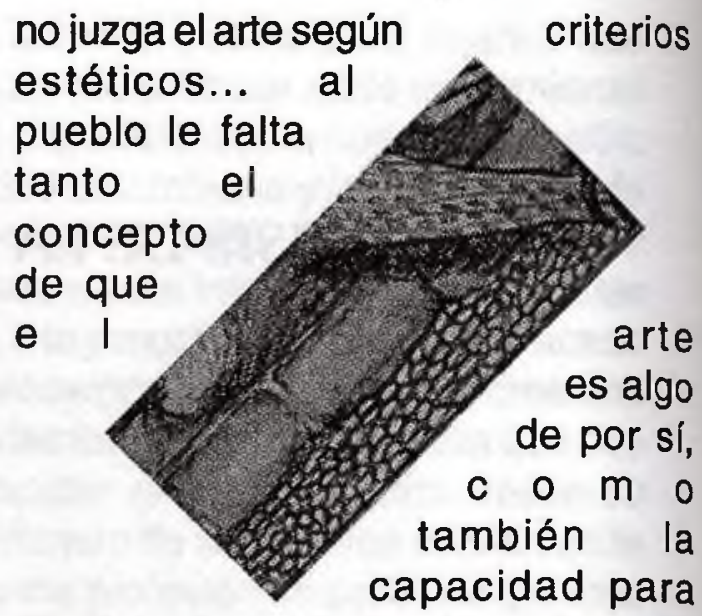

distinguir entre lo mejor y lo peor artísticamente"; su incapacidad creativa: "el pueblo es esencialmente improductivo, no produce apenas sino que la mayoría de las veces sólo reproduce" ${ }^{\prime 3}$; además de otras frases que excluyen la posibilidad de valorar el arte popular como aporte al acervo cultural de la humanidad.

De otra parte, apareció como fenómeno de la revolución industrial y de la democratización de la sociedad, propio del capitalismo, el arte de masas desde principios del siglo XIX. Para Hauser es "arte de masas en doble sentido: de un lado, ofrece pasatiempo artístico uniforme a un público extraordinariamente numerosos, $y$, de otro, produce en masa sus productos uniformes ${ }^{4}$.

En la actualidad tanto la cultura de élites como la popular se ven

1. HAUSER, Arnold. TEORIA DEL ARTE. Madrid. De. Guadarrama. S.A. 1975 p.279-282.

2. Ibídem. p. 291

3. Ibídem, p. 294-295.

4. Ibídem, p. 331 
amenazadas por la cultura homogenizante de masas la cual se conceptúa como el "acelerado flujo de las producciones culturales que responden comercialmente a un mercado que se acerca al de los productos industriales de consumo masivo ${ }^{5}$.

Sin embargo, las culturas más vulneradas corresponden a la cultura popular. Se debe aclarar que "el cambio que estamos viviendo no es la destrucción de la cultura por medio de algunos productos culturales, sino el reemplazo de culturas populares locales por productos culturales masivamente difundidos. Nada demuestra que las industrias culturales destruyan la gran cultura universalista: todo evidencia que destruyen las tradiciones y las culturas locales. No existe casi ya situación alguna que un etnólogo pueda llamar tradicional e indígena. En todos lados se ha transformado la alimentación, la vestimenta, las fiestas, las lenguas, mediante la penetración de elementos difundidos, sobre todo desde Estados Unidos, que conquistó un casi monopolio de la producción y de la difusión de esa cultura de masas ${ }^{6}$.
Las denuncias respecto a la crisis de la cultura y el arte no son nuevas ya Georg Lukacs y la Escuela de Frankfurt se habian pronunciado al respecto. Sobre esta problemática Lukacs explicitó el concepto de reificación: "es decir, la transformación del sujeto en objeto - es el verdadero modo de producción capitalista. La tarea del capitalismo es la transformación del mundo en objeto. Esta es también la tarea de la ilustración. Lo que hace el capitalismo es superar la objetividad de la naturaleza propia de la ilustración a través de la objetivación del hombre"7.

Entonces, se puede decir que la hegemonía capitalista considera a la naturaleza y al hombre como simples objetos sojuzgados y desecha-bles, como simples recursos del sistema de producción. No obstante, Lukacs indica que la esencia y origen de la crisis de la cultura y el arte se centra en la "reificación de la conciencia", en lo cual coincide la Escuela de Frankfurt; o sea, que la estructura mental del hombre "reificación del espíritu mismo", -se encuentra también cosificada, convertida en objeto ${ }^{8}$. Con ello tanto la vida material como la in-

5. TOURAINE, Alain. "Crisis de la cultura"en MAGAZIN DEL ESPECTADOR No. 344. Bogotá. Noviembre 26 de 1989. p. 20.

6. Ibídem. p. 21

7. USCO. "La crisis del arte y la cultura"en módulo PLANEACION, POLITICA, ESTADO Y MODERNIDAD. Neiva, 1995. p. 149-150.

8. Ibídem. p. 150. 
terior se encuentran alienadas para servir al orden de producción imperante.

De acuerdo con la Escuela de Frankfurt la crisis de la cultura y el arte presenta tres aspectos básicos: "EI primero y más profundo es la crisis de la obra de arte, en sí misma. El arte ha sido situado en una

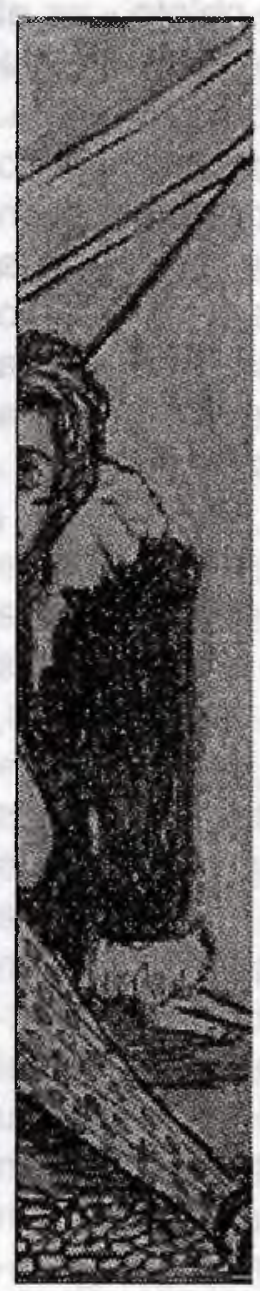
posición insostenible. La tecnología ha destruído su autenticidad esencial y su autonomía. Ya no puede existir por sí mismo como mediación de la belleza, sino que depende de las cosas que le son exteriores. La masa, acontecimiento social creado por la tecnología, hace depender el arte de la política y a la política del arte. En cualquier caso el arte pierde su esencia; debe negar su belleza promulgando el horror fascista o tiene que rechazar la negatlvidad afirmando la estructura social vigente. La obra de arte perdió dialécticamente su posición anterior, pero no ha creado dialécticamente un momento nuevo que le permita seguir siendo arte. La segunda crisis surge de la primera y es la crisis de la cultura en general.
La cultura misma deviene afirmativa. Peor aún, gracias a la pérdida de sus componentes estéticos y de sus imperativos institucionales y políticos sé vuelve mediocre. La cultura, más que configurar la conciencia, se erige como negación de la conciencia. Se establece como repetición vacía de una consigna, puesto que la repetición es la única tarea que le queda después del fracasdo del arte. El estado de la cultura moderna representa el oscurecimiento de la conciencia humana y, precisamente, su vaciedad, le proporciona elasticidad completa haciéndola inmune a la oposición por medio de una combinación de fuerzas y capacidad de absorción. Por último, existe la crisis de las instituciones, la industria cultural levanta una superestructura institucional sobre la transformación tecnológica del arte y la cultura. Como respuesta a los imperativos racionalizados de toda la estructura burocrática y como respuesta a la racionalidad que sustenta el sistema económico y político en su conjunto, la industria cultural es inexpugnable ante los ataques culturales y políticos" ${ }^{\prime \prime}$.

La misma Escuela de Frankfurt afirma que existe "una crisis aún más profunda, pero vinculada a la crisis cultural: la crisis de la psiquis humana", en la cual las manifestaciones culturales son solamente el "aspecto objetivo del problema del sujeto"10. Esta crisis de la psiquis de la humanidad ha conllevado al "triunfo del mal gusto y del horror", acoplado con el fracaso de la crítica cultural en

9. Ibídem, p. 174-175.

10. Ibídem, p. 176 
la ruptura de la autocomplacencia propia de una cultura insuficiente $y$ distorsionada" ${ }^{11}$.

El anterior estado de cosas se ha fraguado al interior del capitalismo ya que: "en el capitalismo la cultura se convierte en una industria más. Pero a diferencia de las funciones de otras industrias, la función de la industria cultural es fundamental para el mantenimiento del sistema. Es a través de la estructura y contenido de la cultura como se constituye la conciencia; y es por medio de la constitución de una conciencia reprimida como el sistema se mantiene"12.

De manera más específica, la cultura dentro del ámbito capitalista cumple una "función social interna, concreta, y es creada por medio de la compleja maquinaria artística que opera bajo la protección del sistema.

Su propósito es, por otra parte, afirmar las condiciones sociales existentes y, por otra, proporcionar una salida segura y absurda al descontento -a través del arte puro- (socialmente sin sentido)"13.

Para sintetizar, Jurgen Habermas explicó que el capitalismo convertía la cultura "en objeto de ocio, sin ningún vínculo especial con los procesos sociales"o en saber especializado de profesionales. Al tiempo considera
Habermas al arte como un potencial para relativizar la c u I t u r a hegemónica" ve en el arte una contracultura que se enfrenta a este intento del capitalismo de aislar la cultura de la sociedad y de erigir el éxito y los beneficios como criterio último"14.

\subsection{SITUACION DE LA PROBLEMATICA DE LA CULTURA Y EL ARTE}

Para situar y posteriormente efectuar una propuesta de solución desde la formación artística, se hace indispensable considerar los siguientes cuestionamientos: Cuál es el problema central del arte y la cultura? ; cuál problema cultural nos identifica?: qué cultura debemos crear y estimular?; cuáles son las características de nuestra cultura?; qué es cultura popular?; qué hacer por la cultura popular?

El arte como creación intelectual hace parte de cada cultura humana y su producción se expone a una constante manipulación por parte de la clase que dirige la sociedad. Es considerado fundamental tomar el planteamiento

11. Ibídem, p. 145-146

12. Ibídem, p. 168.

13. Ibidem. p. 150

14. MESA, José Alberto. "El concepto de interacción en el planteamiento de J. Habermas"en revista UNIVERSITAS PHILOSOPHICA No. 14. Bogotá, De. U.J. 1990. 
de Guillermo Bonfil Battalla sobre "EI problema del control cultural", como:

\section{el problema central DE LA CULTURA Y EL ARTE}

Bonfil Battalla dice: "1. El problema consiste en definir una relación significativa entre sociedad y cultura que sirva como herramienta heurística para entender mejor los procesos culturales que ocurren cuando dos grupos con cultura diferente e identidades contrastivas están vinculadas por relaciones asimétricas (de dominación/subordinación). En tal sentido se exploran las posibilidades que ofrece el empleo de la noción de control cultural... Por control cultural se entiende la capacidad de decisión sobre los elementos culturales... ${ }^{15}$.

Sugerimos tener en cuenta el grado de participación en la toma de decisiones sobre los elementos culturales por cuanto de ello depende

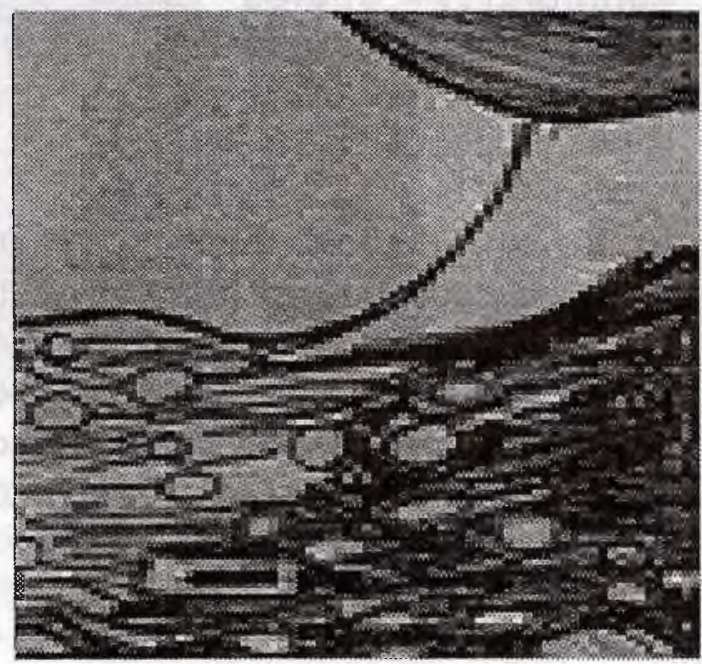

el tipo de valores culturales y la calidad de cultura que debemos transmitir a las nuevas generaciones.

\section{ALguNAS CARACTERISTICAS DE LA CULTURA}

Bonfil Battalla, continua diciendo: "4. La relación que buscamos es la que establece entre quien (grupo social) decide y sobre qué (elementos culturales) decide.

En una primera aproximación, las posibilidades se esquematizan como sigue:

"Cultura AUTONOMA: El grupo social posee el poder de decisión sobre sus propios elementos culturales...

"Cultura IMPUESTA: Ni las decisiones ni los elementos culturales puestos en juego son del grupo social: los resultados, sin embargo, entran a formar parte de la cultura total del propio grupo"...

"Cultura APROPIADA: Los elementos culturales son ajenos, en el sentido de que su producción y/o reproducción no están bajo el control cultural del grupo, pero este los usa y decide sobre ellos."

"Cultura ENAJENADA: Aunque los elementos culturales siguen siendo propios, la decisión sobre ellos es expropiada". ${ }^{16}$

15. BONFIL BATTALLA, Guillermo. "Lo propio y lo ajeno "Revista cultura popular APORTES No. 28. Centro Documentación DIMENSION EDUCATIVA, Bogotá, p.25.

16. Ibídem, p.26-27. 
Si analizamos la cultura de nuestro país encontramos que existen rasgos de todas las anteriores características, sin embargo, es posible asegurar que la de menor representación es la cultura AUTONOMA.

Teniendo en cuenta los principios funda-mentales de enten-dimiento y de las relaciones entre los pueblos de la tierra, consideramos necesario $y$ factible desarrollar en el proyecto educativo una Cultura Apropiada, que seleccione permanen-temente los aportes positivos de cada cultura o pueblo para buscar cada día la verdadera "cultura humana".

\section{TIPOS DE} CULTURA

Los estudiosos de las ciencias sociales coinciden en afirmar que existen muchas tendencias culturales que responden a diferentes ámbitos geográficos del planeta; así, Rodolfo Stavenhagen afirma: "Podemos hablar pues, de una gran cadena que incluirá los siguientes elementos: cultura universal-cultura regional (grandes "civilizaciones")cultura nacional- cultura étnica, en la cual los distintos elementos se encuentran estre-chamente entrela- zados en la dinámica del desarrollo contem-poráneo y cuyos límites no son fáciles de establecer.

No cabe duda, por lo demás, que cada uno de los elementos de la cadena influye en los otros. Así, prácticamente no existen hoy en día culturas étnicas minoritarias que no hayan absorvido distintos elementos de las llamadas culturas nacionales, regionales y universal. Por otra parte, todas ellas contienen a su vez rasgos o elementos tomados de los demás. Por ello es necesario subrayar que estos conceptos de cultura han de considerarse no como factores estáticos e inmutables, sino más bien como procesos dinámicos en constante interacción"17.

Esta aclaración nos hace pensar en la proliferación de manifestaciones culturales en nuestro país y las fusiones o mezclas que allí se puedan encontrar. Esto nos aporta una riqueza en actitudes y aptitudes para comprender, asimilar, apropiar, interpretar y re-crear buscando un desarrollo integral como personas.

Stavenhagen, trata otras denominaciones de cultura que no vamos a

17. STAVENHAGEN, Rodolfo. "La cultura popular y la creación intelectual" Revista APORTES 28, Cultura popular Dimensión Educativa. Bogotá, Colombia p.19. 
considerar por ahora: queremos detenermos en lo siguiente: "Es necesario hacer una última distinción, que tal vez sea la que con mayor frecuencia se utiliza en el lenguaje cotidiano. Esta se refiere a la cultura de élite o elitista, cultura de masas y cultura popular... Así cuando se trata de cultura elitista o cultura "culta"se piensa en lo más refinado y especializado de la producción cultural, no sólo la que es resultado del trabajo minucioso y la creación genial de una auténtica élite especializada de productores de bienes culturales, sino también la que es consumida y usufructuada por las élites económicas y políticas dominantes... Las clases dominantes y los aparatos ideológicos del Estado promueven y difunden en primer lugar sus propios modelos y valores culturales.

Durante las últimas décadas, han cobrado creciente importancia mundial en la difusión de estos modelos culturales en los medios de comunicación masiva. Las características de estos medios han generado, a su vez, formas culturales que han llegado a llamarse "cultura de masas" ${ }^{18}$.

"La cultura de masas"creada por el mercantilismo que sostiene el sistema económico capitalista, manipula a favor de sus intereses los productos culturales de las "culturas de élites" y la cultura popular.

Como hemos visto anteriormente la "cultura de masas"es una producción de la "cultura mercantilista"generada por la "cultura burguesa"'elitista"para sostener el sistema económico capitalista. Esta "cultura" manipula ideológicamente y económicamente los productos o creaciones de las demás culturas.

\section{CULTURA POPULAR}

Rodolfo Stavenghagen plantea: "Este concepto, que también puede ser tildado de amplio y ambiguo, se refiere a los procesos de creación cultural emanados directamente de las clases populares, de sus tradiciones propias y locales, de su genio creador cotidiano. En gran medida, la cultura popular es cultura de clase, es la cultura de la clase subalterna: es con frecuencia la raíz en la que se inspira el nacionalismo cultural, es la expresión cultural de los grupos étnicos minoritarios.

La cultura popular incluye aspectos tan diversos como las lenguas minoritarias en sociedades nacionales en que la lengua oficial es otra; como las artesanías para uso doméstico y decorativo: como el folclor en su acepción más rigurosa y más amplia; como formas de organización local paralelas a las instituciones sociales formales que caracterizan a una sociedad civil y política dada: como el cúmulo de conocimientos empíricos no considerados como "científicos", etc. ${ }^{19}$

18. Ibídem, pág. 20-21

19. Ibídem. pág. 21 
Consideramos necesario hacer una aclaración de la definición respecto de las expresiones artísticas.

Cuando se habla de "folclor on su acepción más rigurosé más amplia", además de li costumbres, ritos, mitos, $s$ incluyen allí las expresione musicales, corporales : visuales, poéticas, literarias y la arquitectura.

Retomando el problema de la "crisis del arte y la cultura"tenemos que reconocer que a las expresiones artísticas de la cultura popular (cultura dominada), no ha tenido la oportunidad de participar en la toma de decisiones sobre el quehacer con su producción. Es considerado lógico que en esta etapa del desarrollo social democrático y participativo se brinden y creen los espacios para que esta colabore con un desarrollo real de la sociedad contemporánea.

\section{¿QUÉ HACER CON LA CULTURA POPULAR?}

Es necesario iniciar un proceso de análisis y autoreconocimiento sobre el etipo y característica de cultura popular que deseamos desarrollar en cualquier proyecto educativo.

Al respecto queremos dar a conocer los planteamientos del doctor Adolfo Colombres sobre: Elementos para una teoría de la cultura Latinoamericana.

Colombres plantea la función de las culturas de la siguiente manera: a) La cultura burguesa (dominante "superior") desarrolla un proyecto ideológico que se impone a las masas: se noracteriza por confundir la ıción con nacionalismo y el jeblo con población. b.) La ultura popular dice que efleja la realidad social y todas sus contradicciones.

Teniendo en cuenta que los postulados fundamentales para el desarrollo humano parten de la solución de necesidades $y$ problemas reales de los actores sociales. En la cultura popular los actores sociales están representados por el pueblo.

\section{EL CAMBIO CULTURAL}

Al respecto el anterior mencionado autor nos dice: "El cambio vimos, es una constante de toda cultura viva. Pues bien, se me dirá; pero no es lo mismo este cambio llamado evolutivo que el cambio aculturativo? No, no es lo mismo. Si lo fuera, habría que bendecir entonces la aculturación. EI cambio dentro de los grupos subalternos puede tener fundamentalmente dos direcciones: hasta donde quiere el opresor (cambio aculturativo), o hacia donde quiere el mismo pueblo (cambio evolutivo). En el primer caso el pueblo padece la historia, en el segundo la hace, es su principal protagonista y no un simple objeto de acción... El cambio aculturativo culmina en la asimilación, en el cruce de la frontera étnica con la pérdida de la identidad cultural, y 
probablemente también de la independencia política y económica. El cambio evolutivo defenderá la identidad cultural, por más cambios que se operen en los factores de identificación...."

En resumen, en el cambio evolutivo la cultura occidental enriquecerá y acelerará el desarrollo de la cultura del grupo. En el cambio aculturativo la va aniquilando, consumiéndose poco a poco, como un cáncer" ${ }^{20}$.

Continuando con el autor Colombres: ..."Y la forma, la forma más elaborada de esta cultura es la conciencia nacional, que regirá al hombre en su vida política y social, permitiéndole defenderse de sus enemigos. Almicar Cabral, el asesinado líder de Guinea Bissau, decía a su vez: "He aquí la razón de que a las masas populares no se les plantee, ni puede plantearseles el problema del retorno a las fuentes, o del renacimiento cultural; las masas son las portadoras de la cultura, ellas mismas son la fuente $y$, al mismo tiempo, la única entidad verdaderamente capacitada para preservar y crear la cultura, es decir, para hacer historia"... "Es necesario apoderarse del futuro, no entregar a nadie esta potencialidad, pues como decía Fanon, "La humanidad espera algo más de nosotros que esa imitación caricaturesca y en general obscena"... "Siempre es bueno que el hombre conozca otras culturas, y no sólo superficialmente. Pero antes debe conocer bien su propia cultura, consolidarla en su interior hasta que opere como resorte protector, como punto inalienable de mira. Recién entonces estará en condiciones de transitar por el mundo sin peligros. $Y$ si se trata de un artista, sabrá que materiales tomará en cuenta en el momento de la creación, y a quien dirigirá su obra, por donde canalizar sus mas profundas búsquedas"21.

Frente a los destrozos causdos por la cultura hegemónica y la masificación alienante de la misma, como queda señalado, se hace indispensable establecer un "diálogo de saberes entre las expresiones de la cultura popular y de élite"22, como un frente que garantice la permanencia de la diversidad cultural, la recuperación de la identidad nacional, el desarrollo de la creatividad, la expresión de nuestros imaginarios, individuales y colectivos, la manifestación de nuestros sueños y fantasías, el perfeccionamiento de nuestra sensibilidad, en fín de nuestro real desarrollo humano frente a la sojuzgante y expoliadora cultura homogenizante que se pretende extender a toda costa.

20. COLOMBRES, Adolfo "Elementos para una teoría de la cultura latinoamericana. Revista APORTES 28 Cultura Popular. Dimensión Educac. Bogotá. Colombia, pág. 49.

21. Ibídem. p.52-56.

22. GARCIA, Canclini Nestor. "Culturas Hibridas estrategías para entrar y salir de la modernidad". México. Ed. Grijalbo, 1995, Pág. 200 


\subsection{LA EDUCACION ARTISTICA FRENTE A LA PROBLEMATICA DE LA CULTURA Y EL ARTE}

El proceso histórico por el cual ha atravezado nuestro país definió tres etapas culturales: a) Conquista y colonia o cultura impuesta; b.) Independencia y república o cultura aceptada; c.) Postcolonialismo o cultura homogenizante ${ }^{23}$.

De esta manera la falta de autonomía es secuela del avasallamiento sistemático impuesto desde la misma Conquista, con el cual el paradigma extranjero fue introproyectado, determinando su asunción de manera consuetudinaria. Así, el etnocentrismo hispánico, impuesto como modelo racial y cultural, por medio de exacciones caracterizadas por la violencia, modeló la negaciónm de nuestro ser. Por tal razón y secuencialmente fueron aceptados el francés, el inglés $y$, finalmente, el norteamericano.

Bajo esta perspectiva el anterior proceso explicita no sólo la dependencia económica, política y cultural sino también la negación de la posibilidlad de cambio en los sectores dominantes de la población.

Como bien se sabe, las etapas culturales enunciadas fueron y son difundidas por modelos pedagógicos signados por la dominación. Por tal razón Sonía Pérez Bioti explica: "En principio, y vinculado con un proyecto de máximo grado de aculturación, las órdenas jesuitas, agustinas y dominicas generaron los primeros métodos "civilizatorios". Su objetivo: anular todo vestigio cultural no occidental-cristiano en el mundo cotidiano y espiritual del indio, el negro y posteriormente el criollo. Esta pedagogía de la dominación inició el sustrato de inseguridad cultural y racial que arrastraría América Latina por siglos y que dejó una huella en el siquismo colectivo de nuestros pueblos expresados en la admiración, imitación y dependencia de la cultura blanca occidental. También generó una especial cimarronería cultural, de códigos altamente cerrados e identificatorios, que a través del pensamiento mágico ritual así como la tradición oral subsiste en nuestros días como expresión de una cultura de resistencia. Posteriormente, en la etapa de la cultura aceptada o admitida al decir de G. Weimberg, llegaron a

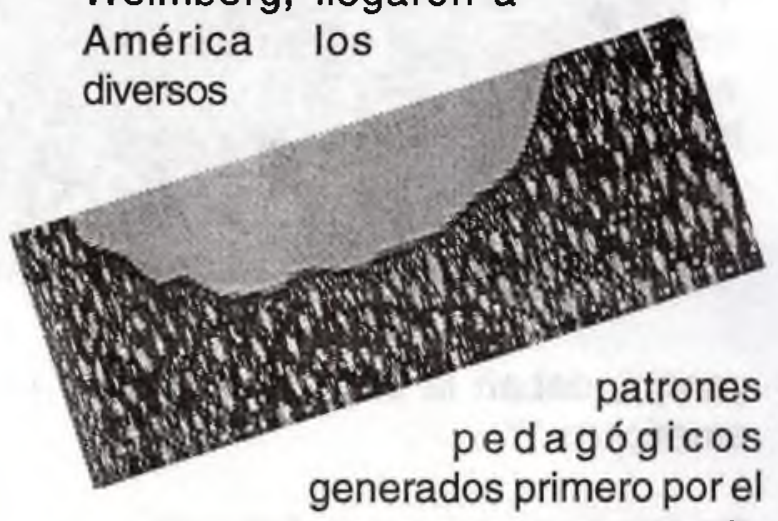

iluminismo, luego por la necesidad de fuerza capacitada del

23. PEREZ Bioti, Sonia. "La educación artística como estrategia de identificación para los pueblos latinamericanos"en Revista ARTE, LITERATURA Y CULTURA. Fotocopias sin más datos, p.32 
capitalismo industrial que nos acostumbraron a interpretar nuestros contextos socio-culturales con la lógica histórica europea y nos entrenaron a pensar y utilizar vías de acción alejadas de nuestras realidades, y que tuvieron un máximo de representatividad y gravitación continental a pesar del intento de algunos pensadores americanos que alertaban que "ni el libro europeo, ni el libro cionalización de la cultura, ejercida por los poderosos medios de comunicación masiva que homogeniza los modelos, valores y gustos impuestos por el capitalismo, produce el fenómeno de la transculturación; es decir, "el producto dinámico de una refuncionalización permanente de lo diverso que lo conforma con lo nuevo que integra y por ello la innovación será siempre mayor que la tradición"25.

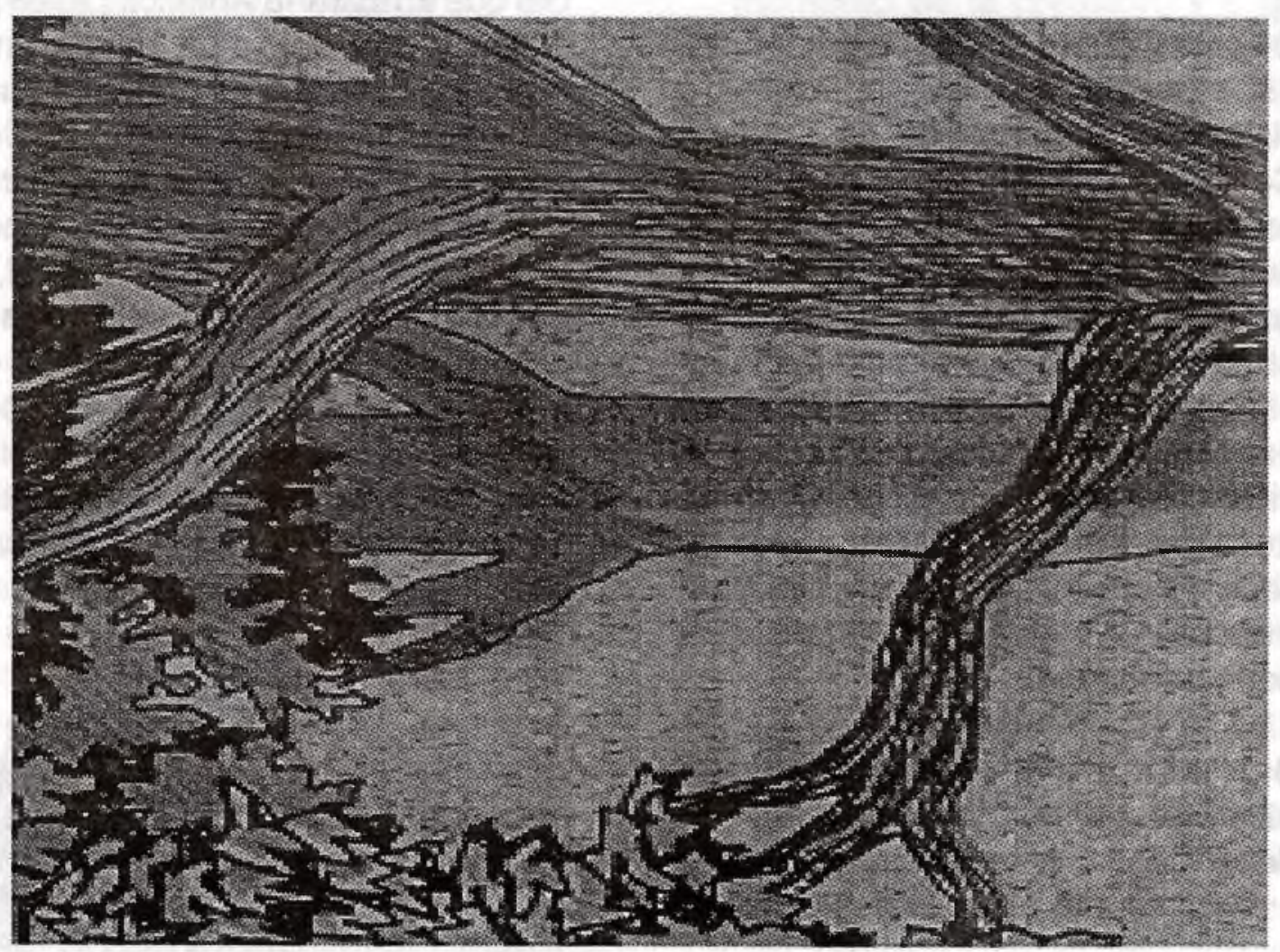

yanqui, daban la clave del enigma americano." ${ }^{24}$

De otra parte, también es verdad que actualmente la permanente interna-
Sustentados en las razones anteriores se colige que la educación debe cumplir funciones dinamizadoras de la cultura, orientadas de manera crítica a develar nuestro ser histórico y

24. Ibídem, p.34-35

25. Ibídem, p.34 
nuestro estar presente, al tiempo que motiva a justipreciar nuestros auténticos valores.

Respecto a la educación artística Sinia Pérez afirma: "El arte, por incluir emoción y razón, por establecer una relación especial de subjetividad a subjetividad, puede contribuir en América Latina al necesario cambio de autopercepción que necesitan esto pueblos para superar los sentimientos de alejamiento y desvalorización de sus propias raices que una educación aculturadora sedimentó durante siglos contribuyendo a un total prejuiciamiento de sus distintos valores culturales. La consecución de este objetivo debe motivar reflexiones con respecto a las estrategias pedagógicas que se instrumenten para la educación artística, profesional o no en el área"26.

Vista así la estética postmodernista impuesta por lo procesos de transculturación, desde los centros de poder a la periferia, puede ser relativizada al posibilitar la hibridación de temas, técnicas, formas y contenidos procedentes de distintos tiempos y culturas. Es decir, que el "carácter multiideneoestético del arte contemporáneo" permite la coexistencia de las expresiones del llamado "arte culto" con el estigmatizado "arte popular"27.

En lo que concierne dice Sonia Pérez B. "La educación artística puede coadyuvar al conocimiento y reconocimiento de las culturas tradicionales y populares, y a la comprensión de su lógica particular a través de la constatación directa de sus carácteres vivos... Todos estos referentes del subconciente colectivo sirven para acopiar y refuncionalizar lo válido de nuestra cultura y para diseñar estrategias modernizadoras que rescaten y diversifiquen el saber acumulado ${ }^{28}$.

Por todo ello, es nuestra obligación, recobrando las mejores experiencias y sueños utópicos, levantar las banderas de la cuarta etapa cultural. Esta acción debe encontrarse fundamentada en el reconocimiento y valoración étnico-cultural de nuestro pueblo hasta encontrar los caminos que conduzcan al desarrollo socialse

26. Ibidem.

27. García Canclini, Nestor. Op. Cit. Pág. 226-228.

28. Pérez Biotti, Sonia. Op. Cit. Pág. 39. 